\title{
Reflections on Educational Inequality and Its Countermeasures Yan Chen
}

Jingchu University of Technology, Jingmen, 448000, China

\author{
Keywords: Educational Equality, Countermeasures, Reflections
}

\begin{abstract}
The General Secretary Xi Jinping specially mentioned the problem of deepening educational comprehensive reform in the Third Plenum of 18th CPC Central Committee. Problems emerging in current educational field are diversified. The common people mainly pay attention to educational equality problem, and the phenomena of educational inequality have been highlighted and have presented a series of consequences. The General Secretary Xi Jinping's speech has offered important enlightenment for our solving inequality problems in educational field.
\end{abstract}

\section{Introduction}

The General Secretary Xi Jinping mentioned the problem of deepening educational comprehensive reform in the Third Plenum of 18th CPC Central Committee that energetically promoting educational equality, perfecting impoverished students subsidization system, building effective mechanism which uses information-based means to expand coverage of high-quality education resources, gradually narrowing the gap between regions, city and country, and schools, balancing the configuration of compulsory education resources in city and country, carrying out standardized construction of public schools and rotation system for the principal and teachers, canceling key schools and key classes, solving problems of school choices, and treating both symptoms and root causes in order to relieve students' homework burden. However, problems in Chinese educational field have in fact been highlighted in recent years because of historical limitation and development of the reform and opening-up policy. Problems of promoting educational equality mentioned in the General Secretary Xi Jinping's speech are of great practical significance. Problems brought by gaps between regions, city and country, and schools have caused actual educational inequality.

\section{Representation of educational inequality phenomenon}

Since the 1990s, the proportion of rural students in prestigious universities has been failing constantly, presenting a phenomenon of "the lower the family background is, the worse the schools are”. An educationalist named Yang Dongping directed a project "Research on higher education equality problems in China". Through investigation and survey, research group achieved a conclusion that the proportion of rural students in Chinese national key universities has been failing since the 1990s. There are fewer and fewer rural students studying in prestigious universities. Is it caused by the effect of urbanization progress that is to say urban students who take part in college entrance examination are far more than rural students? The answer is "No". In the national college entrance examination this year, rural students took 62 percent. Obviously, there are other reasons for the phenomenon that fewer and fewer rural students are studying in prestigious universities. In fact, the results whether students can be admitted to prestigious universities or not are the comprehensive representation of their learning process before college entrance examination. Rural students' unsatisfying examination results or differences with urban students are caused by many years of educational accumulation. Rural students have already lost many years before they take part in college entrance examination, because they lack educational resources. In the final analysis, the declining proportion of rural students in national key universities is a representation of educational inequality. 


\section{The fact that rural education resources are lacked}

Rural students' educational resources are quite different from that of urban students. There are also differences that commonly exist for different schools in the same region, which is the primary cause for rampant school-selecting phenomenon. Scarcity of rural education resources is mainly presented in the following aspects:

\section{Situations of rural education human resources}

Teachers are the most important human resources in educational process. Teachers' quality directly determines the teaching quality. But there are problems at present in rural area like weak teacher resources, low overall quality, and serious job-hopping problems of excellent teachers.

\section{Rural teachers are lacked and the structure distribution is uneven}

At present, professional teachers for music, sports, art, computer, geography, English, etc are extremely lacked in broad rural schools. Many schools can't find proper professional teachers, so they have to give up opening one or even several subjects. Sometimes one teacher teaches several subjects at the same time. What they teach isn't what they have learned and their majors are not in demand, so the teaching effects are imaginable. Because of regional disparity and resource differences in city and country, rural teachers unidirectionally flow to cities and towns, backbone teachers are mainly in cities and towns, and gap of rural and urban teacher resources become larger and larger. The discrepancy of rural and urban teachers' treatment and schools' infrastructure conditions makes it rather difficult to supplement excellent rural teacher resources. Many students majoring in music and art prefer to stay in towns and open an auxiliary class after graduation. They are not willing to teach in rural areas. The uneven construction distribution of rural teachers and discipline shortage directly influence the carrying out of rural quality-oriented education, restricting the development of rural education.

\section{Rural teachers generally have low education background and professional level}

The education background of rural teachers is uneven, many teachers never accept any standard normal education, and they don't timely improve their education background and obtain Teacher Certification through further education after engaging in teaching profession. Therefore, the actual teaching abilities of many teachers are rather limited. There are problems like ageing knowledge structure and outdated educational concept. The teaching quality is difficult to be ensured. From perspective of teachers' knowledge structure, teachers without Teacher Certification are lack of pedagogy and psychology knowledge. The lack of teachers' compulsory curriculum knowledge will cause unscientific teaching methods. From perspective of lesson preparation, teaching plan, blackboard design, blackboard writing, and instruction language, there are problems in varying degrees. Teaching means are relatively old-fashioned, and teaching art is comparatively lacked. Spoon-feeding teaching takes up a large proportion in teachers' teaching activity organization, causing that students are unable to accept and digest the knowledge they have been taught. After students have ideological problems, teachers are likely to adopt simple and rude treatment which is harmful for students' healthy growth. All these will cause unsatisfactory teaching effects. Distance between rural and urban teachers' quality makes it difficult for rural students to enjoy high-quality education resources. Rural students are unable to truly enjoy the right of accepting education equally in process of receiving education.

The loss of excellent teachers is serious and common teachers lack opportunities of further education and training

For reasons that rural and urban teachers' wages and welfare differ greatly, and the rural conditions are so hard, many teachers are not content with teaching in rural schools. Once there are chances they will flow to schools with better conditions in towns or economical developed areas, which to some degree causes the loss of excellent rural teachers. Rural schools are unable to keep excellent teachers, which will definitely influence teaching quality and affect the improvement of students' academic record to a certain degree. At the same time, many teachers are dissatisfied with 
their income and living environment, so they will muddle along in teaching process. In addition, restricted by influences of geographical conditions and economic conditions, there are few chances for rural teachers to receive further education and training and teachers don't have the power to actively receive economic condition. Some teachers have no correct understanding of receiving new educational idea and teaching methods, holding that these educational idea and teaching methods make no difference. They still adopt traditional methods to deal with education under the new situation and rural students can't enjoy scientific education mode suitable for their physiological characteristics, which will affect their growth profoundly.

\section{Software resource construction status of rural education}

Educational software resources mainly refer to the network educational resources for learning like textbook, courseware, video, wonderful class, etc. In aspect of courseware resources, firstly many rural schools are short of multimedia teaching equipment. They can't use multimedia courseware and rural students can't get favorable network resources. Secondly, even though there is certain multimedia teaching equipment, many aged teachers in rural areas don't know how to use it and don't have the ability to make multimedia courseware and make use of online education resources. Although software is favorable, it can't be fully applied because of teachers' limited level. Therefore, rural teachers and students don't truly enjoy the benefit brought by information technology. Compared with urban teachers and students who fully receive online learning resources, they place themselves in a more disadvantaged position, causing larger educational inequality. For example, when learning computer knowledge, rural students can't conduct practical training with one computer for each student. When learning English, their pronunciation accuracy and listening ability cultivation will also be limited. These existing actual situations place rural students in an obvious disadvantaged position in examinations.

\section{Hardware resource construction status of rural education}

With the development of Chinese education and promotion of quality-oriented education, society's demands for talents don't merely stay at the stage of knowing what it is but pay more attention to the practical ability of solving problems like why and how. However, the cultivation of students' practical ability undoubtedly needs to be explored in teaching activities. Textbooks are no longer the sole curriculum resources. Multimedia, laboratory and library gradually become more important in students' learning process. In rural areas, outdated hardware construction is a kind of universal phenomenon. Many schools are lack of hardware equipment because of capital limitation. Constructions like laboratory, library, reading room and multi-media classroom in rural schools are seriously outdated. Laboratories are short of experimental apparatus and experimental drugs, making many laboratories a decoration for dealing with superior inspection. Libraries are lack of excellent books suitable for children. Small quantity and slow update are not good for cultivation of children's good reading habits. There is no special place for reading rooms and no environment for students' learning and thinking. Multi-media classrooms lack corresponding equipment like computers and projectors, students have to accept traditional teaching organization form. Imperfect hardware equipment makes rural students unable to expand their horizon better and improve their learning ability. They have to face the unequal fact of educational resource distribution. In more remote areas, even basic teaching conditions like classroom, blackboard, desks and chairs, etc can't be fulfilled.

\section{Several suggestions for dealing with educational inequality}

Aiming at the current existing phenomenon of educational inequality, we put forward the following countermeasures in accordance with the General Secretary Xi Jinping's effective mechanism which uses information means to expand the coverage of high-quality education resources, and instructions of gradually narrowing the gap between regions, town and country, and schools, and balancing the configuration of rural and urban compulsory education resources.

Firstly, we should energetically improve rural teachers' treatment. Although we advocate teachers' selfless contribution, material needs are the normal needs for everyone under the reform and opening-up policy today. If we want to keep excellent teachers, we should improve rural 
teachers' treatment. Rural teachers' salaries should be proportionately higher rather than much lower than that of urban teachers. Improving rural teachers' treatment can on the one hand make up for the facts of worse rural environment and on the other hand make rural teachers content with teaching in rural areas.

Secondly, we should improve teachers' quality and strictly carry out teacher position system. Teachers' importance in educational process has determined that improving rural teachers' quality should be the priority of promoting educational equality. Improving rural teachers' quality can provide rural teachers with chances of receiving further education and training in urban excellent brother schools, viewing and emulating excellent teachers' classroom organization, truly learning methods and really grasping the teaching spirit.

Finally, we should improve the hardware equipment of rural education. Expanding the coverage of high-quality education resources with information means needs advanced hardware equipment. If the hardware equipment is lacked, courses like music, computer, dance, etc that many students want to learn can't be developed let alone the sharing of education resources and balanced development of education. Many schools even have no projector until now. Writing merely with chalk will greatly influence classroom contents. Many teachers will write on a small blackboard beforehand and bring it to classroom in order to save classroom time. A significant aspect of improving the hardware equipment of rural education is increasing national input.

Education is a major event that concerns the country's future, national well-being and the people's livelihood. National development can't do without advanced science and technology, advanced science and technology can't do without excellent talents, and excellent talents can't do without advanced educational idea. Education plays a vital role in turning our country from a populous nation to a big country of manpower resource. Educational equality will make rural areas spirited, let more rural children enjoy the giant achievements of the reform and opening-up policy, and undoubtedly bring harmonious good news to our country's development.

\section{Acknowledgments}

This paper is one of the research results of a project named "Exploration of Student Quality Cultivation in Chinese Characteristics Basic-level Universities" in Jingchu University of Technology in 2012. (Project number: SK201221)

\section{References}

[1] Communique of the Third Plenum of 18th CPC Central Committee [R]. Source: Xinhuanet: http://news.xinhuanet.com/house/suzhou/2013-11-12/c_118113773.htm

[2] Zhao Jianfang. Ponders on improving rural teachers' quality 【J】 . Journal of Daqing Junior College 2000 (1).

[3] Zhu Zhongqin. Existing problems and countermeasures of rural education resources【J】 . Literary Education, 2009 (7).

[4] Liao Longlong. Investigation of rural teachers’ professional quality conditions 【J】 . Modern Distance Teaching, 2005 (2).

[5] Pang Lijuan. Problems, reasons and countermeasures of current rural primary and secondary schools in China [J]. Educational Development Research, 2006( 2B).

[6] Feng Junlian, Tang Songlin. Responsibility and pursuit of modern rural teachers[J]. Teacher Education Research, 2011(3). 